\title{
New thiadiazine derivatives with activity against Trypanosoma cruzi amastigotes
}

\author{
Susana Muelas ${ }^{1}$, Rossanna Di Maio ${ }^{2}$, Hugo Cerecetto ${ }^{2}$, Gustavo Seoane ${ }^{2}$, Carmen Ochoa ${ }^{3}$, José Antonio \\ Escario $^{1}$ and Alicia Gómez-Barrio ${ }^{1}$
}

\author{
${ }^{1}$ Departamento de Parasitología, Facultad de Farmacia, Universidad Complutense, Ciudad Universitaria s/n, 28040 Madrid, \\ Spain; \\ ${ }^{2}$ Departamento de Química Orgánica, Facultad de Químicas, Universidad de la República, cc 1157, 11800-Montevideo, Uruguay; \\ ${ }^{3}$ Instituto de Química Médica, Consejo Superior de Investigaciones Científicas, C/ Juan de la Cierva 3, 28003 Madrid, Spain
}

Key words: anti-Trypanosoma cruzi drugs, amastigotes, J774 macrophages, cytotoxicity assay

\begin{abstract}
The cytotoxicity of 18 new 1,2,6-thiadiazin-3,5-dione 1,1-dioxides was evaluated. This group of products was previously assayed against epimastigotes of Trypanosoma cruzi and some of them showed a high antiprotozoal activity. Thereafter 13 compounds with a high anti-epimastigote activity and low cytotoxicity were selected to be assayed against amastigotes. Some of the products showed the same or even lower cytotoxicity than nifurtimox and benznidazole, but most of them were very toxic for macrophages at $100 \mu \mathrm{g} / \mathrm{ml}$. Only one of the compounds had an anti-amastigote activity similar to that of reference drugs at $10 \mu \mathrm{g} / \mathrm{ml}$, but unfortunately this disappeared at lower concentrations.
\end{abstract}

Chagas' disease is a major health problem in South and Central America, affecting 16-18 million people (WHO 1991). In spite of such high prevalence, only two synthetic compounds, nitroheterocycles nifurtimox $\left(\right.$ Lampit $\left.^{\circledR}\right)$ and benznidazole $\left(\right.$ Rochagan $\left.^{\circledR}\right)$, are in use (Croft et al. 1997). Both are effective in the early stages of trypanosomiasis, but are practically useless in the chronic disease. Only 50\% of patients are parasitologically healed after treatment (Kirchhoff 1994). The limited efficacy as well as their toxic side effects justify the continued research for trypanocidal substances.

In this way, new 1,2,6-thiadiazine-3,5-dione 1,1dioxides have been synthesised (Di Maio et al. 1999). In previous works were reported the anti-Trypanosoma cruzi properties of 3,5-diamino-4-(5'-nitro-2-furfurylidene) $4 H$-thiadiazine 1,1-dioxide and those of some 4heteroarylidene-1,2,6-thiadiazine-3,5-dione 1,1-dioxide (Atienza et al. 1992, Herrero et al. 1992). The presence of nitro substituents in the pentaheterocyclic moiety, as a source of free radicals, seems to be a factor that increases anti-T. cruzi activity (Di Maio et al. 1999).

Previous anti- $T$. cruzi activity of these new thiadiazines was evaluated on epimastigotes. Almost all of them were effective at $100 \mu \mathrm{g} / \mathrm{ml}$. Some of them remained active at $10 \mu \mathrm{g} / \mathrm{ml}(3 \mathrm{a}, 3 \mathrm{~b}, 3 \mathrm{c}, 3 \mathrm{~d}, 4 \mathrm{a}, 4 \mathrm{~b}, 4 \mathrm{c}$ and $4 \mathrm{~d}$ ), but none at $1 \mu \mathrm{g} / \mathrm{ml}$ (Di Maio et al. 1999). After the first screening, new in vitro studies have been performed to analyse the nonspecific toxicity and antiamastigote activity of the compounds.

\section{MATERIALS AND METHODS}

Cell culture. Murine J774 macrophages were grown in plastic $25 \mathrm{ml}$ flasks in RPMI 1640 medium (Sigma) supplemented with $20 \%$ heat inactivated $\left(30 \mathrm{~min}, 56^{\circ} \mathrm{C}\right)$ foetal calf serum (FCS) and $100 \mathrm{IU}$ penicillin $/ \mathrm{ml}+100 \mu \mathrm{g} / \mathrm{ml}$ streptomycin, in a humidified $5 \% \mathrm{CO}_{2} / 95 \%$ air atmosphere at $37^{\circ} \mathrm{C}$ and subpassaged once a week.

Parasites. Trypanosoma cruzi Chagas, 1909 (Y strain) was grown at $28^{\circ} \mathrm{C}$ in liver infusion tryptose (LIT) supplemented with $10 \%$ FCS and antibiotics. Epimastigote forms were harvested on day 14 of culture (stationary phase) and washed three times in Grace medium. To induce metacyclogenesis, parasites were then cultured in fresh Grace medium supplemented with $10 \%$ FCS and haemin $(25 \mu \mathrm{g} / \mathrm{ml})$. Nine days after cultivation at $28^{\circ} \mathrm{C}$, metacyclic forms were counted in order to infect macrophages. The proportion of metacyclic forms was around $30 \%$ at this stage.

Cell infection. J774 macrophages were detached by EDTA-PBS (ethylendiamine tetraacetic acid- phosphatebuffered saline) treatment and counted by a haemocytometer. Cells were seeded at a density of 50,000 cells/well in 24-well microplates (NUNC) with rounded coverslips on the bottom. Then 500,000 trypomastigotes and fresh medium were added, giving a final volume of $2 \mathrm{ml}$. Attachment and invasion of host cells were allowed for $24 \mathrm{~h}$.

Cytotoxicity to macrophages. $\mathrm{J} 774$ macrophages were seeded $(70,000$ cells/well) in 96-well flat-bottom microplates (NUNC) with $200 \mu 1$ of medium. The cells were allowed to attach for $24 \mathrm{~h}$ at $37^{\circ} \mathrm{C}$ and then exposed to the compounds $(100,10$ and $1 \mu \mathrm{g} / \mathrm{ml})$ for another $24 \mathrm{~h}$. Afterwards, the cells were washed with PBS and incubated $\left(37^{\circ} \mathrm{C}\right)$ with 3-(4,5- 
dimethylthiazol-2-yl)-2,5-diphenyltetrazolium bromide (MTT) $0.4 \mathrm{mg} / \mathrm{ml}$ for $60 \mathrm{~min}$. MTT solution was removed and the cells solubilised in dimethyl sulphoxide $(100 \mu 1)$. The extent of reduction of MTT to formazan within cells was quantified by measurement of $\mathrm{OD}_{595}$ (Hattori and Nakanishi 1995). Each concentration was assayed three times and six cell growth controls were used in each test. The assays were twice performed. Cytotoxicity percentages $(\% \mathrm{C})$ were determined as follows:

$$
\% \mathrm{C}=[1-(\mathrm{ODp}-\mathrm{ODpm}) /(\mathrm{ODc}-\mathrm{ODm})]^{*} 100
$$

where ODp represents the mean $\mathrm{OD}_{595}$ value recorded for wells with macrophages containing different doses of product; ODpm represents the mean $\mathrm{OD}_{595}$ value recorded for different concentrations of product in medium; ODc represents the mean $\mathrm{OD}_{595}$ value recorded for wells with macrophages and no product (growth controls), and ODm represents the mean $\mathrm{OD}_{595}$ value recorded for medium/control wells. The cytotoxic dose $50\left(\mathrm{CD}_{50}\right)$ was defined as the concentration of drug that decreases $\mathrm{OD}_{595}$ up to $50 \%$ of that in control cultures.

Anti-amastigote activity. After cell infection, culture medium was removed, and suspensions of compounds in fresh medium were added to final concentrations non-toxic for macrophages (i.e. concentrations $<\mathrm{CD}_{50}$ ). After $48 \mathrm{~h}$, the coverslips were fixed and stained with May Grünwald Giemsa and the number of amastigotes/100 macrophages (No. A/100 $\mathrm{Mø)}$ were estimated. Anti-amastigote activity (\%AA) was expressed as:

$$
\% \mathrm{AA}=\left[1-(\text { No. A/100 Mø)p/(No. A/100 Mø)c }]^{* 100}\right.
$$

All experiments were run at least in triplicate and the results are given as mean \pm standard deviation (Mendez et al. 1999).

Source of compounds. The synthesis of the 18 new 1,2,6thiadiazine-3,5-dione 1,1-dioxides was described elsewhere (Di Maio et al. 1999). Their structures are shown in Fig. 1. Nifurtimox (Lampit; Bayer, Buenos Aires, Argentina) and benznidazole (Rochagan; Roche, Rio de Janeiro, Brazil) were used as reference drugs in every assay.<smiles>[R]N1SN([R])C(=O)CC1=O</smiles>

$$
\begin{aligned}
& 2 \mathrm{R}_{2} \text { absent } \\
& \mathbf{3} \mathrm{R}_{2}=5 \text {-nitro-2-thienyl } \\
& \mathbf{4} \mathrm{R}_{2}=5 \text {-nitro-2-furyl } \\
& 5 \mathrm{R}_{2}=p \text {-nitrophenyl }
\end{aligned}
$$<smiles>[R]C=C1C(=O)N([R])SN([R])C1=O</smiles>

$$
\begin{aligned}
& \text { a } R_{1}=\text { cyclohexyl } \\
& \text { b } R_{1}=\text { n-butyl } \\
& \text { c } R_{1}=\text { n-hexyl } \\
& \text { d } R_{1}=\text { benzyl } \\
& \text { e } R_{1}=\text { phenethyl }
\end{aligned}
$$

Fig. 1. Chemical structure of 1,2,6-thiadiazine-3,5-dione 1,1dioxides assayed. Structure of derivatives $2\left(R_{2}\right.$ absent) is shown on the left, that of derivatives 3,4 and 5 ( $\mathrm{R}_{2}$ nitrosubstituted) is shown on the right.

\section{RESULTS}

Table 1 shows the cytotoxicity of these new compounds. As it can be seen compounds non-substituted in $4^{\text {th }}$ position were not toxic for macrophages at 100 $\mu \mathrm{g} / \mathrm{ml}$, while the rest of compounds $(3,4$ and 5 derivatives) with the exception of $5 \mathrm{a}, 5 \mathrm{~d}$ and $4 \mathrm{e}$ had a $\% \mathrm{C}>\mathrm{CD}_{50}$, thus they could not be assayed afterwards against amastigotes at this concentration. At lower concentrations there was no toxicity.

Activity against amastigotes is shown in Table 2. None of the compounds had activity greater than the reference drugs. Compound $3 \mathrm{c}$ had good trypanocidal effect at $10 \mu \mathrm{g} / \mathrm{ml}$, but this disappeared at $1 \mu \mathrm{g} / \mathrm{ml}$. Compound $3 \mathrm{a}$ had high activity at $100 \mu \mathrm{g} / \mathrm{ml}$ but also a relatively high toxicity (close to $\mathrm{CD}_{50}$ ). At $10 \mu \mathrm{g} / \mathrm{ml}$ and $1 \mu \mathrm{g} / \mathrm{ml}$ it maintained some effect against amastigotes.

\section{DISCUSSION}

The complexity of the clinical entity caused by Trypanosoma cruzi makes the pharmacological screening of new compounds a hard and tedious job. Sensitivity of extracellular stages to drugs is usually higher than that of intracellular amastigotes (Martínez Díaz et al. 2000), so that the first screening on epimastigotes may produce a number of false positives. However, screening against epimastigotes maintained in liquid medium is easier and more economic than test on cellular cultures of amastigotes. In our opinion potential antichagasic drugs must be first selected on extracellular epimastigotes and thereafter on amastigote-infected cells.

Other 1,2,6-thiadiazine-3,5-dione 1,1-dioxides have been previously synthesised and assayed against $T$. cruzi (Atienza et al. 1992, Herrero et al. 1992), and 5-nitro-2furyl derivatives had important activity, both against epimastigotes and amastigotes. The presence of nitro substituents, resembling in this way the structure of nifurtimox and benznidazole, seems to enhance the activity of these compounds. That is the reason why new 1,2,6-thiadiazines with 5-nitro-2-thienyl, 5-nitro-2furyl and $p$-nitrophenyl substituents were synthesised along with their analogues without this heterocyclic moiety. The nitro substituents do not only enhance the anti-trypanosome activity but also the nonspecific toxicity. Thus analogues without the heterocyclic moiety were not toxic at $100 \mu \mathrm{g} / \mathrm{ml}$, but only $2 \mathrm{c}$ had some anti-amastigote activity and at the same time, was the most toxic $(\% \mathrm{C} \approx 37 \%)$. In general, compounds with the heterocyclic moiety were considered toxic at 100 $\mu \mathrm{g} / \mathrm{ml}(\% \mathrm{C} \geq 50 \%)$, but these values hardly ever reached $\% \mathrm{C}$ close to $90-100 \%$, that the real toxic products have. As for the anti-amastigote activity, compound 3a had an important one at $100 \mu \mathrm{g} / \mathrm{ml}$ that was maintained at lower concentrations; at $1 \mu \mathrm{g} / \mathrm{ml}$ 
Table 1. Cytotoxicity (\%) of thiadiazine derivatives to $\mathrm{J} 774$ macrophages at different drug concentrations. Means of three tests \pm standard deviation.

\begin{tabular}{|c|c|c|c|c|c|c|}
\hline \multirow{2}{*}{ Product } & \multicolumn{2}{|c|}{$100 \mu \mathrm{g} / \mathrm{ml}$} & \multicolumn{2}{|c|}{$10 \mu \mathrm{g} / \mathrm{ml}$} & \multicolumn{2}{c|}{$1 \mu \mathrm{g} / \mathrm{ml}$} \\
\cline { 2 - 7 } & Assay 1 & Assay 2 & Assay 1 & Assay 2 & Assay 1 & Assay 2 \\
\hline nifurtimox & $11.7 \pm 3.7$ & $23.9 \pm 11.1$ & $0.6 \pm 3.9$ & $0 \pm 7.3$ & $0.3 \pm 3.5$ & $0.7 \pm 6.3$ \\
benznidazole & $0 \pm 3.8$ & $2.9 \pm 6.8$ & $1.9 \pm 5.4$ & $7.1 \pm 2.7$ & $6.9 \pm 6.1$ & $8.1 \pm 1.6$ \\
2b & $17.9 \pm 8$ & $21.9 \pm 5.6$ & $0 \pm 6.8$ & $0 \pm 7.9$ & $3.6 \pm 9.0$ & $0 \pm 4.2$ \\
2c & $0 \pm 1.3$ & $0 \pm 8.2$ & $0 \pm 1.9$ & $0 \pm 5.8$ & $0 \pm 4.0$ & $0 \pm 5.3$ \\
2e & $39.8 \pm 8.1$ & $34.7 \pm 2.1$ & $6.5 \pm 3.9$ & $0 \pm 8.2$ & $0 \pm 6.6$ & $0 \pm 5.6$ \\
3a & $48.3 \pm 8.6$ & $48.1 \pm 10.6$ & $16.2 \pm 3.8$ & $7.0 \pm 7.0$ & $0.4 \pm 4.9$ & $0 \pm 8.2$ \\
3b & $61.2 \pm 6.7$ & $58.6 \pm 6.2$ & $4.0 \pm 2.2$ & $0 \pm 2.6$ & $0 \pm 3.6$ & $0 \pm 4.2$ \\
3c & $94.6 \pm 3.7$ & $94.6 \pm 3.7$ & $4.1 \pm 6.4$ & $1.9 \pm 0.8$ & $0 \pm 1.9$ & $0 \pm 1.1$ \\
3d & $50.9 \pm 2.1$ & $58.2 \pm 7.5$ & $0 \pm 8.8$ & $0 \pm 13.5$ & $0 \pm 3.2$ & $0 \pm 0.2$ \\
3e & $74.3 \pm 1.2$ & $72.8 \pm 2.8$ & $0 \pm 4.6$ & $0 \pm 3.2$ & $0 \pm 12.0$ & $0 \pm 5.9$ \\
4a & $75.0 \pm 1.2$ & $80.1 \pm 4.1$ & $7.7 \pm 4.7$ & $4.6 \pm 5.5$ & $0 \pm 8.9$ & $0 \pm 2.9$ \\
4b & $58.3 \pm 0.9$ & $55.6 \pm 7.3$ & $0 \pm 3.6$ & $0 \pm 5.5$ & $0 \pm 1.7$ & $0 \pm 4.4$ \\
4c & $97.0 \pm 1.0$ & $91.0 \pm 1.2$ & $2.9 \pm 9.0$ & $1.9 \pm 1.2$ & $1.0 \pm 4.2$ & $0 \pm 1.1$ \\
4d & $55.8 \pm 2.8$ & $52.0 \pm 2.4$ & $0 \pm 4.2$ & $1.0 \pm 5.6$ & $4.4 \pm 2.1$ & $10.1 \pm 5.9$ \\
4e & $16.3 \pm 9.3$ & $14.1 \pm 13.7$ & $0 \pm 12.6$ & $0 \pm 18.3$ & $0 \pm 3.7$ & $0 \pm 14.1$ \\
5a & $2.1 \pm 6.7$ & $0 \pm 10.6$ & $8.0 \pm 3.3$ & $0 \pm 4.8$ & $3.1 \pm 2.9$ & $0 \pm 3.3$ \\
5b & $96.6 \pm 4.7$ & $93.5 \pm 2.6$ & $0 \pm 3.6$ & $0 \pm 9.6$ & $0 \pm 6.0$ & $0 \pm 3.1$ \\
5c & $100 \pm 1.3$ & $98.8 \pm 1.6$ & $8.7 \pm 9.0$ & $8.9 \pm 6.3$ & $0 \pm 1.7$ & $4.7 \pm 4.2$ \\
5d & $13.2 \pm 8.0$ & $17.9 \pm 6.8$ & $0 \pm 5.1$ & $0 \pm 3.7$ & $0.2 \pm 4.2$ & $0 \pm 11.6$ \\
5e & $100 \pm 1.3$ & $98.8 \pm 2.8$ & $0 \pm 10.0$ & $0.2 \pm 2189$ & $0 \pm 3.1$ & $7.9 \pm 1.6$ \\
\hline
\end{tabular}

Table 2. Trypanocidal effects of several thiadiazine derivatives on amastigote forms at different drug concentration. Means of at least three tests \pm standard deviation.

\begin{tabular}{|c|c|c|c|}
\hline Product & $100 \mu \mathrm{g} / \mathrm{ml}$ & $10 \mu \mathrm{g} / \mathrm{ml}$ & $1 \mu \mathrm{g} / \mathrm{ml}$ \\
\hline nifurtimox & $95.0 \pm 1.5$ & $84.9 \pm 3.6$ & $67.5 \pm 6.3$ \\
benznidazole & $92.4 \pm 3.8$ & $82.1 \pm 1.5$ & $40.3 \pm 3.1$ \\
2b & $6.6 \pm 5.1$ & $6.6 \pm 18.8$ & $0 \pm 23.9$ \\
2c & $0 \pm 11.5$ & $2.3 \pm 4.1$ & $0 \pm 25.0$ \\
2e & $75.1 \pm 15.7$ & $0 \pm 24.9$ & $0 \pm 14.7$ \\
$3 \mathrm{a}$ & $75.8 \pm 6.4$ & $42.7 \pm 7.1$ & $9.9 \pm 4.5$ \\
3b & $*$ & $65.8 \pm 5.1$ & $0 \pm 6.3$ \\
$3 \mathrm{c}$ & $*$ & $82.2 \pm 2.5$ & $0 \pm 5.6$ \\
3d & $*$ & $0 \pm 3.8$ & $0 \pm 12.0$ \\
$4 \mathrm{c}$ & $*$ & $0 \pm 15.5$ & $0 \pm 23.2$ \\
$4 \mathrm{~d}$ & $*$ & $0 \pm 4.4$ & $4.4 \pm 7.6$ \\
$4 \mathrm{e}$ & $38.2 \pm 7.8$ & $12.0 \pm 10.8$ & $2.5 \pm 13.6$ \\
$5 \mathrm{a}$ & $59.9 \pm 4.2$ & $0 \pm 5.7$ & $0 \pm 11.2$ \\
$5 \mathrm{~b}$ & $*$ & $4.4 \pm 23.7$ & $32.4 \pm 7.3$ \\
$5 \mathrm{~d}$ & $26.2 \pm 15.7$ & $14.2 \pm 6.2$ & $7.4 \pm 4.6$ \\
\hline
\end{tabular}

* toxic doses to macrophages $\mathrm{J} 774$

some activity was left. Although a complete clearance of amastigotes was not observed in any case, the new 1,2,6- thiadiazines assayed are more active that the ones described in previous works.

Based on the trypanocidal activities and the cytotoxicity experiments, the most interesting compound for animal studies of trypanosomal infection is 3a. Further work designed to examine the ability of compound $3 \mathrm{a}$ to provide a cure for $T$. cruzi-infected mice is currently in progress.

Acknowledgements. The authors are grateful to $\mathrm{T}$. McDougall for carefully reviewing the English version of the manuscript. 
ATIENZA J., MARTÍNEZ FERNÁNDEZ A.R., GÓMEZBARRIO A., ESCARIO J.A., HERRERO A., OCHOA C., RODRIGUEZ, J. 1992: Activity assays of thiadiazine derivatives on Trichomonas vaginalis and amastigote forms of Trypanosoma cruzi. Chemotherapy 38: 441-446.

CROFT S.L., URBINA J.A., BRUN R. 1997: Chemotherapy of human leishmaniasis and trypanosomiasis. In: G. Hide, J.C. Mottram, G.H. Coombs and P.H. Holmes (Eds.), Trypanosomiasis and Leishmaniasis Biology and Control. CAB International, Wallingford, Oxon, U.K., pp. 245-257.

DI MAIO R., CERECETTO H., SEOANE G., OCHOA C., ARÁN V.J., PÉREZ E., GÓMEZ-BARRIO A., MUELAS S. 1999: Synthesis and antichagasic properties of new 1,2,6-thiadiazin-3,5-dione 1,1-dioxides and related compounds. Arzneim. Forsch. (Drug Res.) 49: 759-763.

HATTORI Y., NAKANISHI N. 1995: Effects of cyclosporin $A$ and FK506 on nitric oxide and tetrahydrobiopterin synthesis in bacterial lipopolysaccharide-treated $\mathrm{J} 774$ macrophages. Cell. Immunol. 165: 7-11.
HERRERO A., OCHOA C., ATIENZA J., ESCARIO J.A., GÓMEZ-BARRIO A., MARTÍNEZ FERNÁNDEZ A.R. 1992: Synthesis and antiprotozoal properties of 1,2,6thiadiazine 1,1-dioxide derivatives. Arch. Pharm. 325: 509-514.

KIRCHHOFF L.V. 1994: American trypanosomiasis (Chagas' disease) and African trypanosomiasis (sleeping sickness). Curr. Opinion Infect. Dis. 7: 542-546.

MARTÍNEZ DÍAZ R.A., ESCARIO J.A. , NOGAL RUIZ J.J., GÓMEZ-BARRIO A. 2000: Evaluation of drug activity against intracellular forms of Trypanosoma cruzi employing enzyme immunoassay. J. Clin. Pharm. Therap. 25: 4347.

MENDEZ S., NELL M., FERNÁNDEZ-PÉREZ F.J., ALUNDA J.M. 1999: Sensitivity of Leishmania infantum amastigotes to fluorinated L-ornithine analogues. Med. Sci. Res. 27: 87-89.

WHO 1991: Control of Chagas' disease. WHO Technical Reports Series, No. 811: 27-37.

Accepted 12 September 2000 